\title{
A CONSTITUIÇÃO INVERTIDA: A SUPREMA CORTE AMERICANA NO COMBATE À AMPLIAÇÃO DA DEMOCRACIA
}

Gilberto Bercovici

\section{As origens não democráticas da constituição norte- americana}

Há um mito muito forte na historiografia dos Estados Unidos sobre o papel do "mercado" na formação da nova nação. Os propagadores deste mito partem do pressuposto equivocado de que Estado e economia de mercado seriam esferas contrapostas, entendendo toda e qualquer forma de regulação como uma interferência pública na esfera das relações econômicas naturais e privadas. Além disto, para estes autores, a regulação só teria se desenvolvido nos Estados Unidos a partir do século XX. Por sua vez, pesquisadores como William Novak, buscam demonstrar que desde o início da história norte-americana não haveria nenhuma distinção clara entre esfera estatal e esfera da economia de mercado, pelo contrário, a economia norte-americana sempre teria se desenvolvido com forte presença, direta e indireta, do Estado. O comércio, as trocas, a economia como um todo são setores definidos e estruturados politicamente por meio do direito. O mercado é uma criação humana, histórica e politicamente configurada, especialmente, no 
caso norte-americano, por meio do direito e de governos, federal e estaduais, atuantes e que forneceram as condições necessárias para o desenvolvimento econômico dos Estados Unidos. Desenvolvimento econômico este que ia da construção de canais e ferrovias até a transformação do regime jurídico da propriedade e dos contratos. Para Novak, a sociedade norte-americana do final do século XVIII e do século XIX não era, de modo algum, uma sociedade sem Estado ou uma economia do laissez-faire da mitologia liberal, pelo contrário. Tratava-se de uma "sociedade bem ordenada" ( "well-ordered society"), com muitas similaridades em relação ao "Estado de polícia” (Polizeistaat) europeu (Novak, 1996, pp. 83-8, 235-48) ${ }^{1}$.

Durante a Revolução Americana, as treze ex-colônias, agora Estados, logo declararam em vigor as antigas leis sobre propriedade e incorporaram proteções legais específicas aos direitos de propriedade em suas constituições. 108 Apesar de exigirem a qualificação de propriedade para o exercício do sufrágio, entre 1776 e 1787, na realidade, não havia uma efetiva garantia da propriedade. Os governos estaduais procuraram desenvolver seu próprio sistema mercantilista. Em vários Estados havia um enorme ativismo legislativo em matéria econômica. Os excessos dessa legislação envolviam até emissão e desvalorização de moeda. Todos os legislativos estaduais, segundo Forrest McDonald (1985, pp. 101-6, 152-7), violaram os direitos de propriedade, inclusive os direitos dos credores. A agitação popular fez com que vários Estados exercitassem uma intervenção mais radical nas relações de propriedade ${ }^{2}$.

O colapso do crédito público foi um dos principais motivos da convocação da Convenção da Filadélfia. Com a especulação de terras públicas em troca de títulos da dívi-

\footnotetext{
${ }^{1}$ Sobre o "Estado de polícia", ver Tribe (2007), pp. 11-22 e Seelaender (2009).

${ }^{2}$ Sobre a concepção da propriedade como um direito inviolável nas constituições estaduais, ver Adams (2001, pp. 157-160, 187-194).
} 
da pública, havia a necessidade de se restaurar o crédito público. Não existia na América a dívida pública monetizada, como havia na Inglaterra desde 1694, com a instituição do Banco da Inglaterra e a chamada "revolução financeira" inglesa. Para o pagamento das dívidas da guerra revolucionária, ocorreram tentativas de melhorar as rendas do Congresso Continental, que foram vetadas em 1781 e 1783 por Rhode Island e por New York, acarretando a quebra do tesouro da Confederação (Beard, 1986, pp. 31-40; McDonald, 1985, pp. 93-6, 115-9, 170-1).

A crise política e financeira da Nova Inglaterra atingiu os Estados de Connecticut, New Hampshire, Rhode Island e Massachusetts, onde ocorreram várias revoltas armadas de devedores. As mais importantes foram a crise de Rhode Island e a Rebelião de Shay, em Massachusetts. Em 1786, constatou-se que a dívida pública de Rhode Island havia se tornado incontrolável. A assembleia legislativa, então, emite papel-moeda sem lastro, emprestando-o aos cidadãos. Os emprestadores pagariam seus empréstimos e o Estado pagaria seus credores. No entanto, a "moeda" se desvalorizou enormemente e o legislativo declarou que sua aceitação era obrigatória, retirando as garantias de quem se recusasse a recebê-la em pagamento, além de estipular que os devedores cujos credores haviam recusado o papel moeda poderiam cancelar seus empréstimos ao depositá-lo em certas contas e publicar a notícia do pagamento pelos jornais (McDonald, 1985, pp. 173-9).

Em 1786, também os fazendeiros estavam sob uma enorme pressão econômica, insatisfeitos no tocante à política legislativa ordinária e com medo da usurpação das funções governamentais pelas convenções e associações. A Rebelião de Shay, que estourou em setembro de 1786, foi um protesto armado contra a tributação e a cobrança de dívidas dos pequenos proprietários (Szatmary, 1980, pp. 56-69, 91-119; Richards, 2003, pp. 4-42). Embora tenha 
sido derrotada em janeiro de 1787 , a notícia que se espalhou foi a de que milhares de rebeldes estavam prestes a tomar Boston e marchar para o sul, distribuindo todas as propriedades pelo caminho. Esta ameaça, divulgada, entre outros, pelo general Henry Knox, chocou boa parte da elite norte-americana, preocupada com a questão da autoridade e da ordem públicas e com a inabilidade do Congresso Continental em fazer com que os Estados cumprissem suas obrigações (Beard, 1986, pp. 58-60; Wood, 1998, pp. 325-8, 412-3, 465; McDonald, 1985, pp. 176-9; Szatmary, 1980, pp. 70-90).

A reação da elite norte-americana foi entender que o povo, em sua anarquia e licenciosidade, estava pervertendo sua liberdade. John Adams afirmava estar vivendo sob um "despotismo democrático". A instabilidade social e econômica da revolução encontrava sua expressão política nos legislativos estaduais, que elaboravam leis determinando o 110 confisco de propriedade, a emissão de papel-moeda e a suspensão de débitos. Os ataques aos direitos de propriedade eram vistos como excessos inerentes à democracia, que seria incompatível com a segurança, a liberdade e a propriedade. A crise de autoridade e o princípio majoritário pareciam ameaçar os fundamentos do governo republicano na década de 1780 (Beard, 1986, pp. 52-63; Wood, 1998, pp. 403-12; McDonald, 1985, pp. 157-66; Morgan, 1989, pp. 266-7).

Desde setembro de 1786, com a Convenção de Annapolis, que buscou resolver disputas em torno da regulação do comércio entre os Estados, Alexander Hamilton (2001) defendia a convocação de uma convenção nacional para rever os Artigos da Confederação. A proposta desta convenção, que se reuniria na Filadélfia, em maio de 1787, só foi aceita por causa da Rebelião de Shay. A rebelião encorajou o movimento pela reforma dos Artigos da Confederação, com sete Estados manifestando-se favoravelmente à convenção, o que garantiu a aprovação do Congresso Continental em 
21 de fevereiro de 1787. Todos entendiam que a estrutura do governo deveria ser alterada. A licenciosidade não estava levando à anarquia, mas a um despotismo popular. A autoridade do governo central deveria ser fortalecida, para assegurar a liberdade e a propriedade. $\mathrm{O}$ medo da maioria fez a elite norte-americana desejar um novo governo central, revertendo tendências democráticas e reforçando o poder dos magistrados em detrimento do legislativo (Beard, 1986, pp. 61-63; Wood, 1998, pp. 413-25, 430-8, 446-53, 463-7; McDonald, 1982, pp. 90-4; McDonald, 1985, pp. 1-8; Szatmary, 1980, pp. 120-31; Richards, 2003, pp. 125-32) ${ }^{3}$.

O movimento que deu origem à Convenção da Filadélfia de 1787 foi, portanto, eminentemente conservador. Não se queria criar o novo, fazer uma revolução, mas preservar o equilíbrio econômico-social ameaçado. A Revolta de Shay alertou os setores dominantes. Com a Convenção da Filadélfia, o que se buscava era a revisão dos Artigos da Confederação, especialmente no que dizia respeito à regulação uniforme do comércio, interno e externo, e para impedir uma abertura democrática do poder político. O governo central forte não visava tanto os perigos externos, mas sim as ameaças internas, buscando frear e anular as tendências democráticas ou democratizantes. A Convenção da Filadélfia não foi, assim, uma assembleia constituinte. Os seus integrantes eram delegados escolhidos pelos Estados, cujos legislativos também eram eleitos com base no voto censitário, não foram eleitos pelo povo (Aquarone, 1959, pp. 9-16, 143-147; Beard, 1986, p. 64; Morgan, 1989, pp. 267-277; McDonald, 1985, p. 185).

A participação do povo no governo não poderia ser negada totalmente, mas era vista com desconfiança e ceti-

\footnotetext{
${ }^{3}$ Sobre a composição dos vários grupos sociais que atuavam nos Estados Unidos às vésperas da adoção da Constituição e quais deles, pela natureza de sua propriedade, esperavam se beneficiar com o novo sistema, ver a clássica análise de Beard (1986, pp. 19-51).
} 
cismo pelos convencionais da Filadélfia. O seu realismo político fez com que percebessem que, embora contrários à democracia, o governo do Estado não poderia ser a prerrogativa de uma única classe, havendo a necessidade de comprometer a maioria dos cidadãos com a estrutura constitucional. O discurso dos freios e contrapesos ("checks and balances"), presente na Inglaterra do século XVIII, em Montesquieu e na Revolução Americana, contrapõe-se ao discurso da soberania. A soberania decide, enquanto os contrapesos exigem uma negociação para que se chegue a um resultado. $\mathrm{O}$ objetivo declarado dos convencionais da Filadélfia era evitar que o número prevalecesse sobre a qualidade, impedindo a tirania popular e a ascensão política das massas, com um governo que não dependesse do povo. A solução encontrada foi restringir as eleições diretas aos deputados. Os senadores e o presidente seriam eleitos indiretamente e os juízes e funcionários públicos 112 seriam nomeados pelo presidente. O poder executivo seria a força política determinante. O que se buscou foi refinar a escolha popular por meio de sucessivos filtros políticos, defendendo uma concepção elitista de democracia. Deste modo, evitava-se que a maioria ameaçasse a minoria e que houvesse um apelo ao povo no caso de conflito: era impossível uma completa renovação do governo, com os mandatos não coincidentes de deputado, senador e presidente e a vitaliciedade da Suprema Corte (Beard, 1986, pp. 159-62; Aquarone, 1959, pp. 17-28, 38-44, 149-54; Wood, 1998, pp. 474-5, 506-18, 553-62; Hanson, 1988, pp. 184-5) ${ }^{4}$.

Os Federalistas avançaram na ideia de governo limitado, entendendo os governos estaduais muito vulneráveis

\footnotetext{
${ }^{4}$ Hamilton chegou a propor que, em um governo republicano, os ocupantes dos principais cargos fossem eleitos pelo povo. No entanto, os deputados seriam eleitos a cada três anos e os senadores e o presidente, embora devessem ser eleitos diretamente pelo povo, exerceriam seus cargos de forma vitalícia. Ver Stourzh (1970, pp. 48-56).
} 
à pressão e aos humores populares. James Madison preservou o governo republicano em sua forma, mas o separou da democracia, esvaziando seu conteúdo. O medo da política democrática e sua instabilidade foram capitalizados pelos Federalistas para a instituição de um governo representativo em um grande território. $\mathrm{O}$ essencial e suficiente era que o governo derivasse da maioria, mas não fosse controlado por ela. Os Federalistas se utilizaram, deste modo, retoricamente dos argumentos democráticos e populares para justificarem seu sistema aristocrático. No entanto, segundo Wood, ao fazer isto, contribuíram para a não existência de um discurso genuinamente aristocrático e criaram uma tradição liberal que mitigou os antagonismos sociais da política americana, evitando o confronto (Hamilton, Madison \& Jay, 1987, Artigo n. XXXIX; Wood, 1998, pp. 562-4; Hanson, 1988, pp. 179-84).

O princípio teórico utilizado para negar que a maioria pudesse governar, segundo Aquarone (1959, pp. 49-60), foi o da stake-in-society theory: apenas os que têm interesse imediato na ordem social podem participar ativamente da vida política do Estado e determinar seus rumos. O interesse direto e imediato é o da garantia da propriedade, no sentido mais amplo de riqueza. Como a propriedade não era um atributo da maioria, o princípio majoritário não poderia ser o único fundamento do sistema político. A liberdade era entendida como liberdade de adquirir e conservar a riqueza, como destacava Hamilton. Na Constituição de 1787, no entanto, não há qualquer referência à qualificação pela propriedade para votar ou ser votado. As propostas de inclusão expressa deste tópico foram rejeitadas, deixando-se esta decisão para os Estados. Se os Estados não mantivessem as restrições censitárias, não surgiria nenhuma ameaça ao sistema político, pois apenas os deputados eram eleitos diretamente pelo povo (Beard, 1986, pp. 164-8; McDonald, 1982, pp. 117-23). 
A tese de Charles Beard sobre os vários interesses econômicos em jogo na elaboração da constituição americana, embora unilateral, ainda é aceitável. Afinal, para os convencionais da Filadélfia, o objetivo primordial do governo era estabelecer regras que determinam as relações de propriedade para manter o processo econômico. O governo federal não poderia interferir na propriedade privada, inclusive, e especialmente, na propriedade dos escravos. Poderia apenas taxá-la, mas com determinados limites. Em compensação, os Estados não poderiam mais emitir moeda e interferir nos contratos (Hamilton, Madison \& Jay, 1987, Artigos n. IX e X; Beard, 1986, pp. 12-6, 156-8, 176-83; Aquarone, 1959 , pp. $61-9,77-9)^{5}$.

Em relação à célebre "contract clause" da Constituição norte-americana, há, no entanto, um detalhe histórico curioso. Segundo o relato do historiador Forrest McDonald (1985, pp. 270-5), durante os trabalhos da Convenção da 114 Filadélfia de 1787, travou-se uma grande polêmica em torno da proposta de cláusula que garantiria a liberdade contratual. Esta cláusula não foi aprovada pelos convencionais. No entanto, Alexander Hamilton conseguiu inseri-la no texto constitucional norte-americano (em que figura no artigo I, seção $10^{6}$ ) após as votações, na segunda semana de setembro de 1787 , durante a reelaboração do texto aprovado pela Comissão de Estilo.

A Constituição de 1787 não seria submetida ao povo, mas às assembleias estaduais para a sua ratificação. Não se tratava de um pacto entre povo e soberano, mas entre sociedades políticas indissolúveis. O governo federal surgiria do

\footnotetext{
${ }^{5}$ Para a concepção de propriedade para os convencionais da Filadélfia, bem como os interesses econômicos representados por eles, ver Beard (1986, pp. 73151) e McDonald (1985, pp. 10-24, 29-36, 219-224).

${ }^{6}$ Artigo I, Seção 10: "No state shall enter into any treaty, alliance, or confederation; grant letters of marque and reprisal; coin money; emit bills of credit; make anything but gold and silver coin a tender in payment of debts; pass any bill of attainder, ex post facto law, or law impairing the obligation of contracts, or grant any title of nobility" (grifos meus).
} 
consenso dos Estados. Beard destaca que os Artigos Federalistas buscavam, simultaneamente, fornecer argumentos políticos para a ratificação, e convencer os grandes grupos econômicos das vantagens do novo sistema: um governo central forte para garantir a propriedade contra as maiorias e capaz de restringir os abusos legislativos dos Estados. E a disputa entre os interesses econômicos fica evidente no processo de ratificação da constituição (Beard, 1986, pp. 1536, 217-38, 253-91; Aquarone, 1959, pp. 72-7; Morgan, 1989, pp. 277-85; McDonald, 1985, pp. 279-82) ${ }^{7}$.

Charles Beard (1986, pp. 8-12, 188, 324-5) enfatizou a falta de qualquer elemento social ou econômico na análise da constituição norte-americana. Para ele, a constituição de 1787 costuma ser vista com reverência, não compreensão, fora da realidade que a criou, que a condiciona e que por ela é condicionada. A constituição, segundo a crítica análise de Beard, é essencialmente um documento econômico, fundado na concepção de que o direito de propriedade é anterior a ela e deve ser protegido das maiorias populares. A Constituição de 1787 não foi criada pelo povo, nem pelos Estados, mas por um grupo consolidado de interesses econômicos, que era nacional em seus objetivos ${ }^{8}$.

\section{A garantia da propriedade sobre os escravos}

Uma série de compromissos firmados entre os convencionais da Filadélfia fizeram com que a escravidão fosse protegida constitucionalmente por vários dispositivos inseridos no texto, limitando, inclusive, os poderes da União, mas sem ser jamais mencionada explicitamente. Apesar de a

\footnotetext{
${ }^{7}$ Para um levantamento da participação popular durante o processo de ratificação da Constituição de 1787, concluindo pela sua quase total inexistência, ver Beard (1986, pp. 239-52).

${ }^{8}$ Otto Hintze (1964, pp. 442-3), em sentido próximo, entende como uma das grandes tarefas da Constituição de 1787, a criação de um mercado único, favorecendo a expansão capitalista nos Estados Unidos.
} 
Constituição norte-americana não a mencionar diretamente, a "peculiar institution" da escravidão perpassa todo o texto (Waldstreicher, 2009, pp. 57-105) ${ }^{9}$.

Um exemplo é a chamada "cláusula dos três quintos", prevista no artigo I, seção 2, que trata da representação dos Estados no Congresso Nacional ${ }^{10}$. Segundo o texto constitucional de 1787, o número de representantes por Estado na Câmara dos Deputados, assim como a eventual tributação direta por parte da União, seria calculado a partir do número de pessoas livres, incluindo os vinculados a serviços compulsórios (como servidão) e mais três quintos de "all other persons", excluindo-se os índios. "All other persons" eram os escravos, obviamente. A Constituição de 1787, portanto, não apenas admitia a existência de pessoas que não fossem livres, como beneficiava os proprietários de escravos e os Estados escravocratas, pois teriam um número maior de representantes, contabilizados também a partir 116 de três quintos do número total de escravos. Outro dispositivo constitucional vinculado à preservação da escravidão foi o da restrição imposta ao poder do Congresso Nacional de regular o comércio com outras nações e entre os

\footnotetext{
${ }^{9}$ Sobre o compromisso em torno da escravidão na Convenção da Filadélfia, ver Lynd, 1980a e LYND, 1980b. Há, inclusive, constitucionalistas, como Sanford Levinson (1997), que afirmam ser possível compreender a lógica e a estrutura do texto da Constituição norte-americana de 1787 apenas se for dada a devida atenção ao papel que a escravidão teve na sua elaboração e interpretação inicial.

10 "Representatives and direct taxes shall be apportioned among the several States which may be included within this Union, according to the respective numbers, which shall be determined by adding to the whole number of free persons, including those bound to service for a term of years, and excluding Indians not taxed, three fifths of all other persons. The actual enumeration shall be made within three years after the first meeting of the Congress of the United States, and within every subsequent term of ten years, in such manner as they shall by law direct. The number of Representatives shall not exceed one for every thirty thousand, but each State shall have at least one Representative; and until such enumeration shall be made, the State of New-Hampshire shall be entitled to choose three, Massachusetts eight, Rhode-Island and Providence Plantation one, Connecticut five, New-York six, New-Jersey four, Pennsylvania eight, Delaware one, Maryland six, Virginia ten, North-Carolina five, South-Carolina five, and Georgia three" (grifos meus).
} 
Estados. De acordo com o artigo I, seção $9^{11}$, o Congresso não poderia legislar sobre ou restringir a importação de pessoas (leia-se: o tráfico de escravos) por um prazo de vinte anos, ou seja, até 1808 (Fehrenbacher, 2005, pp. 28-47; Waldstreicher, 2009, pp. 3-10).

A preocupação da Constituição de 1787 com a proteção da propriedade foi tão determinante que o texto chegou a prever expressamente uma garantia constitucional aos proprietários de escravos, dando-lhes o direito de recapturar escravos fugitivos no artigo IV, seção 2 ("fugitive slave clause"): "No person held to service or labor in one State, under the laws thereof, escaping into another, shall in consequence of any law or regulation therein, be discharged from such service or labour, but shall be delivered up to claim of the party whom such service or labour may be due".

Este dispositivo foi logo regulamentado pela Fugitive Slave Law, de 12 de fevereiro de 1793, que nenhuma corte jamais declarou inconstitucional (Fehrenbacher, 2001, pp. 40-3; Fehrenbacher, 2005, pp. 209-19). Sua validade, inclusive, assim como a importância do artigo IV, seção 2 da constituição, foi reafirmada no julgamento do caso Prigg v. Pennsylvania, no início de 1842, pela Suprema Corte ${ }^{12}$. Neste caso, Edward Prigg levou à força para o Estado de Maryland a escrava fugida Margaret Morgan e seus filhos, que há cinco anos viviam livremente no Estado da Pensilvânia. Em 1837, Prigg foi indiciado por sequestro e condenado na Suprema Corte da Pensilvânia. O caso chegou à Suprema Corte, cuja decisão foi no sentido de que o direito de recapturar os escravos fugidos era um direito inviolável do proprietário, não podendo ser restringido pela legisla-

\footnotetext{
11 "The migration or importation of such persons as any of the States now existing shall think proper to admit, shall not be prohibited by the Congress prior to the year one thousand eight hundred and eight; but a tax or duty may be imposed on such importation, not exceeding ten dollars for each person".

${ }^{12}$ Prigg v. Pennsylvania - 41 U.S. 539 (1842).
} 
ção infraconstitucional. Desta forma, a lei estadual de 1826, da Pensilvânia, que condenava aqueles que sequestrassem pessoas negras com a intenção de escravizá-las foi declarada inconstitucional (Fehrenbacher, 2001, pp. 43-7; 2005, pp. 219-25). O fundamento da decisão foi o artigo IV, seção 2 da Constituição de 1787, assim descrito pelo célebre Juiz Joseph Story: "The full recognition of this right and title was indispensable to the security of this species of property in all the slave-holding States, and indeed was so vital to the preservation of their domestic interests and institutions that it cannot be doubted that it constituted a fundamental article without the adoption of which the Union could not have been formed"13.

Quando alguns Estados do Norte começaram a se incomodar com esta situação, foi aprovado a Fugitive Slave Law de 18 de setembro de 1850, que reforçou os poderes da União neste setor, ampliando a repressão à fuga de escravos. Alguns Estados se recusaram a aplicar esta nova 118 legislação, como Wisconsin, mas as decisões judiciais neste sentido foram anuladas, em sua função de "garantidora dos valores da comunidade", pela Suprema Corte (Horton \& Horton, 1997, pp. 144-5; Fehrenbacher, 2001, pp. 1602; Kaczorowski, 2002, pp. 29-51; Fehrenbacher, 2005, pp. 225-35, 239-48). Suprema Corte esta, inclusive, responsável pela mais célebre decisão em defesa do sistema escravocrata, tomada no caso Dred Scott v. Sandford ${ }^{14}$, em 1857. Como

\footnotetext{
${ }^{13}$ Prigg v. Pennsylvania - 41 U.S. 611 (1842).

${ }^{14}$ Dred Scott $v$. Sandford - 60 U.S. 393 (1856). Dred Scott era um escravo do Missouri que foi com seu proprietário, John Emerson, para um Estado livre (Illinois) e, depois, para um território federal livre (Minnesota), retornando posteriormente ao Missouri com seu dono. Em 1846, Scott e sua esposa processaram o seu proprietário (que, a partir de 1853, passou a ser John Sanford, executor do testamento de Emerson), alegando que o período de tempo que passaram em território livre os teria tornado pessoas livres. O julgamento da demanda foi bem sucedido na corte local, mas revertido na Suprema Corte de Missouri em 1852. Dred Scott, então, impetrou, em 1854, a mesma ação na justiça federal, agora contra Sanford, e foi esta ação que chegou à Suprema Corte, sendo recebida em 30 de dezembro de 1854. A Suprema Corte, entre os dias 6 e 7 de março de 1857, liderada pelo Chief of Justice Roger B. Taney, negou a apelação de Dred Scott por sete votos a
} 
afirmam James e Lois Horton (1997, p. 155), a legislação de 1850 ameaçou os direitos dos afro-americanos, já a decisão da Suprema Corte no caso Dred Scott proclamou solenemente que esses direitos não existiam. Afinal, de acordo com o voto do Chief Justice Taney, um negro jamais poderia ser cidadão norte-americano: "In the opinion of the court, the legislation and histories of the times, and the language used in the Declaration of Independence, show, that neither the class of persons who had been imported as slaves, nor their descendants, whether they had become free or not, were then acknowledged as a part of the people, nor intended to be included in the general words used in that memorable instrument"15.

É curioso notar que o empenho da Suprema Corte na extensão da garantia dos direitos dos proprietários de escravos antes da Guerra Civil revela a força da rejeição da mesma Suprema Corte à realização dos direitos fundamentais incorporados à constituição pelas $13^{\mathrm{a}}$ e $14^{\mathrm{a}}$ Emendas, depois da Guerra Civil (Kaczorowski, 2002, p. 51).

\section{Da "Constituição de Todos" à "Constituição Invertida"}

As emendas constitucionais que aboliam escravidão e toda forma de servidão compulsória nos Estados Unidos (13 ${ }^{\mathrm{a}}$ Emenda, de 1865) e que instituíam a aplicação igual da lei e o "devido processo legal" ( "due process of law"), a $14^{\mathrm{a}}$ Emenda, de 1868, foram aprovadas sob o discurso da ampliação da cidadania, da criação da "Constituição de Todos" ("Everyman's Constitution") (Graham, 1968, pp. 4-10, 20-1). Paradoxalmente, a aplicação destas emendas pela Suprema Corte, particularmente a $14^{\mathrm{a}}$ Emenda, vai trans-

dois (os votos dissidentes, que garantiam a liberdade de Dred Scott e sua esposa, foram dados por John McLean e Benjamin R. Curtis). Para uma longa e detalhada análise dos argumentos utilizados nas várias decisões do caso Dred Scott, ver Fehrenbacher, 2001, pp. 239-65, 267-83, 285-414.

${ }^{15}$ Dred Scott v. Sandford - 60 U.S. 393, p. 406, entre várias outras passagens neste mesmo sentido. 
formar o discurso da "Constituição de Todos" ( "Everyman's Constitution") na realidade da "Constituição Invertida" ( "Inverted Constitution") ${ }^{16}$.

Esta mudança foi profunda no sistema jurídico norte-americano e esteve centrada no instituto da corporação (a grande empresa, a sociedade anônima). Afinal, no início do século XIX, eram poucas as corporações estruturadas no país, geralmente constituídas para prestarem serviços públicos (como transporte) ou para atuarem nas áreas de seguros ou bancos. $\mathrm{O}$ modelo vigente era o mesmo do período colonial inglês: para a instituição de uma corporação, era necessária a aprovação de uma "carta” ( "charter") específica pelo Poder Legislativo em cada caso. A prática legislativa, assim, determinava, em cada Estado, a política para as corporações. Tratava-se de uma concessão, por parte do poder público, de um privilégio para um empreendimento que poderia, então, realizar sua incorporação, vinculando-se 120 a deveres e obrigações especiais. Os estatutos da corporação, deste modo, existiam apenas como uma concessão ou garantia do poder político soberano. Os direitos, deveres, privilégios e imunidades que seriam aplicáveis àquela associação para a realização de negócios só poderiam ser defini-

\footnotetext{
${ }^{16}$ No mesmo sentido, ver Beatty (2007, pp. 109-11). Uma das principais interpretações sobre a "inversão da Constituição" é a chamada "Teoria da Conspiração" ( "Conspiracy Theory"), defendida a partir dos anos 1930 por vários autores, como Charles Beard e Mary Beard, especialmente na sua obra The Rise of American Civilization, de 1927. Essa teoria se inspira nos argumentos utilizados pelo ex-congressista Roscoe Conkling, um dos integrantes da comissão que, em 1866, redigiu a $14^{\mathrm{a}}$ Emenda, durante o julgamento do caso San Mateo na Suprema Corte, em 1882, quando Conkling atuou como advogado da ferrovia. Segundo o próprio Conkling, a $14^{\mathrm{a}}$ Emenda foi feita para proteger as corporações. Por isto, o texto da emenda utilizaria a expressão "person" e não a expressão "citizen". Hoje a maior parte dos autores, especialmente depois das exaustivas pesquisas de Howard Jay Graham, entende que não há evidências que comprovem a "Teoria da Conspiração", o que não significa que não possa ter havido influência das corporações na elaboração do texto por meio de congressistas a elas vinculados. Ver Graham, 1968, pp. 3063, 70-97, 440-490 e Hurst, 2004, pp. 66-8. O texto da argumentação de Conkling durante o julgamento do caso San Mateo na Suprema Corte está reproduzido em Graham, 1968, pp. 595-610.
} 
dos pelo processo legislativo, não por um acordo particular (Hurst, 2004, pp. 13-30, 132-52; Horwitz, 1990, pp. 109-39; Friedman, 2005, pp. 129-39; Novak, 1996, pp. 105-6) ${ }^{17}$.

A primeira intervenção importante da Suprema Corte no regime jurídico das corporações ocorreu em 1819, com o caso Dartmouth College v. Woodward ${ }^{18}$. Neste caso, John Marshall liderou a decisão que determinava que os Estados não poderiam interferir nas "charters" das corporações, sob pena de estarem violando a cláusula constitucional de proteção aos contratos (a célebre "contract clause"). Dartmouth College era uma corporação pública (não visava realizar negócios) de New Hampshire, cuja "charter" havia sido modificada por uma lei estadual. Para Marshall, a "charter" equivalia a um contrato celebrado entre o Estado e a corporação, portanto, não poderia ser modificada pela Assembleia Legislativa, sob pena de violação à proteção constitucional da liberdade contratual. A decisão da Suprema Corte, na realidade, consistiu em uma séria limitação à soberania popular, retirando dos órgãos políticos parte do controle sobre questões econômicas e sociais, sob a justificativa de, com essa limitação, estar protegendo os investimentos e a propriedade privada (Hurst, 2004, pp. 16-7, 62-4; Friedman, 2005, pp. 136-7; Hovenkamp, 1991, pp. 20-3) ${ }^{19}$.

A partir da década de 1870, a Suprema Corte interpreta a $14^{\mathrm{a}}$ Emenda de modo a aplicá-la a direitos econômicos, como o direito de propriedade e a liberdade contratual, não propriamente aos direitos civis. Para a Suprema Corte, a "pessoa" que tinha os direitos assegurados nos termos da $14^{\mathrm{a}}$ Emenda não era o homem livre, mas a empresa, a corporação (Lerner, 1932-1933, pp. 671-2, 682-3, 690-4; Graham,

\footnotetext{
${ }^{17}$ Sobre as várias teorias da natureza jurídica das corporações utilizadas no decorrer do século XIX pelos autores norte-americanos, inspirados em autores como Otto von Gierke e Ernst Freund, entre outros, ver Horwitz (1994, pp. 70-8, 89-105).

${ }^{18}$ Dartmouth College v. Woodward - 17 U.S. 518 (1819).

${ }^{19}$ Para uma interpretação um pouco distinta, vide Novak (1996, pp. 106-11).
} 
1968, pp. 13-7; Hurst, 2004, pp. 65-70; Friedman, 2005, pp. 396-7; Hovenkamp, 1991, pp. 93-6; Beatty, 2007, pp. 1529). Ou seja, há uma inversão da aplicação da $14^{\mathrm{a}}$ Emenda, gerando o que parcela da historiografia jurídica norte-americana vai chamar de "inverted constitution" (Graham, 1968, pp. 18, 20, 31, 293-4).

A inversão da aplicação da $14^{\mathrm{a}}$ Emenda foi formulada pioneiramente por um ex-Juiz da Suprema Corte, John Archibald Campbell, que atuou como advogado no caso Slaughterhouse ${ }^{20}$, decidido em 1873. Neste caso, a Assembleia Legislativa da Louisiana concedeu a dezessete açougueiros reunidos em uma empresa ("Crescent City Live Stock Landing and Slaughterhouse Company”), o monopólio do manejo e abate de animais em várias regiões do Estado, inclusive New Orleans, por vinte e cinco anos. Apesar da oposição de centenas de açougueiros, privados de seus meios de vida, o Poder Judiciário Estadual manteve a lei e o caso chegou à

122 Suprema Corte. O advogado dos açougueiros, John Archibald Campbell, levou, pela primeira vez, o argumento do "laissez faire" como parte integrante da constituição norte-americana à Suprema Corte.

Para Campbell, o monopólio criado na Louisiana imporia uma servidão involuntária aos consumidores do Estado, o que violaria a $13^{\mathrm{a}}$ Emenda. Além disto, o monopólio seria contrário à primeira seção da $14^{\mathrm{a}}$ Emenda, porque suspendeu privilégios e imunidades de centenas de açougueiros, cidadãos dos Estados Unidos, negando a eles igual proteção da lei e os privando de liberdades essenciais e de propriedade sem o devido processo legal. Para Campbell, a $14^{\mathrm{a}}$ Emenda foi feita para assegurar a liberdade individual, a propriedade privada e a segurança contra a legislação arbitrária, injusta e parcial dos governos. Campbell argumentou pelo direito do indivíduo desenvolver uma atividade eco-

${ }^{20}$ Butcher's Union Slaughterhouse Case - 111 U.S. 746 (1883). 
nômica, equiparando a liberdade individual à liberdade de empresa e à liberdade de competição.

A Suprema Corte manteve a legislação da Louisiana com base em um argumento de natureza racial do Juiz Samuel Miller, que entendeu que os "privilégios e imunidades" e a "igual proteção da lei" do texto da $14^{a}$ Emenda só se aplicariam para proteger o status dos escravos recém libertados. Embora Campbell tenha sido derrotado por cinco a quatro na Suprema Corte, o importante no Slaughterhouse Case é o fato da argumentação do chamado "laissez faire constitutionalism" ter sido trazida à Suprema Corte e ter sido incorporada aos votos dos quatro juízes vencidos, notadamente o Juiz Stephen Field, que vai insistir nesta argumentação em vários outros casos importantes (Lerner, 1932-1933, pp. 692-4; Twiss, 2001, pp. 42-62; McCurdy, 1975, pp. 971-8; Horwitz, 1994, pp. 69-70; Kens, 1997, pp. 118-28; Gillman, 2004, pp. 64-8; Kaczorowski, 2005, pp. 140-88; Beatty, 2007, pp. 117-47) ${ }^{21}$.

O principal destes casos, que marca a inversão da constituição, é o caso Santa Clara $^{22}$, de 1886. Neste caso, a partir do voto do Juiz Stephen Field, a Suprema Corte admitiu expressamente que as empresas, as corporações, estavam protegidas sob a $14^{\text {a }}$ Emenda, estendendo às empresas o status constitucional de "pessoa". Com sua interpretação defensora do "laissez-faire", o Juiz Field justificava a expansão da jurisdição e da discricionariedade da Suprema Corte, visando proteger a sociedade de si mesma. Ao atribuir à Suprema Corte o poder de rever toda e qualquer ação governamental, Field, na prática, estava condenando a maior parte da legislação regulatória do uso da proprieda-

\footnotetext{
${ }^{21}$ Hovenkamp, por sua vez, interpreta a decisão do Slaughterhouse Case como uma decisão correta, pois se tratava de uma medida de saúde pública necessária para o benefício da população. Ver Hovenkamp (1991, pp. 116-24). Em sentido próximo, vide Novak (1996, pp. 230-233).

${ }^{22}$ Santa Clara County v. Southern Pacific R. R. - 118 U. S. 394 (1886).
} 
de. Sua posição favorável às ferrovias, inclusive, era comprovada pela amizade e constante troca de ideias e informações com John Norton Pomeroy, professor da Hastings Law School, na Califórnia, amigo de Stephen Field e advogado das ferrovias (Graham, 1968, pp. 112-7, 121-30, 14950, 391-414, 568-78) ${ }^{23}$.

O Juiz Stephen Field teve que justificar a aplicação da cláusula da "igual proteção da lei" às corporações, embora o texto da $14^{\mathrm{a}}$ Emenda tenha sido escrito para proteger “pessoas”. Para Field, todas as garantias e salvaguardas existentes no texto constitucional para proteger a propriedade possuída pelos indivíduos deveriam ser invocadas para a proteção da propriedade das corporações. De acordo com suas palavras, proferidas no caso San Mateo, em 1882: "Looking at the object of the amendment, it must be admitted that it was intended primarily for the protection of the rights of natural persons; its language is mainly applicable to them. If it also 124 include artificial persons, as corporations, whenever its language is susceptible of application to them, it must be because the artificial entity is composed of natural persons whose rights are protected in those of the Corporation. It may be that the chain which binds the individual into a single artificial body, does not keep them in their united form from the protection of the amendment. Corporations are not citizens, - the term applies only to natural persons, - and yet they are treated, as citizens within the clauses of the constitution which defines the judicial power of the United States, and declares that it shall extend to controversies between citizens of different states" ${ }^{\prime 24}$.

Com base nas considerações do Juiz Stephen Field, a Suprema Corte se manifestou, no início do caso Santa Clara,

\footnotetext{
${ }^{23}$ Para a reprodução das cartas enviadas, entre 1881 e 1884, a John Pomeroy pelo Juiz Stephen Field, nas quais, entre outros temas, há referência aos casos de interesse das ferrovias que estavam sendo apreciados pela Suprema Corte, ver Graham (1968, pp. 101-9). Sobre as relações entre Stephen Field e as ferrovias, ver, ainda, Beatty (2007, pp. 169-170).

${ }^{24}$ County of San Mateo v. Southern Pacific R. Co. - 13 F. 722 (Circuit Court, D. California, 1882).
} 
por meio de uma declaração do Chief Justice Morrison Waite, com uma decisão peremptória, totalmente sem justificativas ou precedentes: "The Court does not wish to hear argument on the question whether the provision in the Fourteenth Amendment to the Constitution which forbids a state to deny to any person within its jurisdiction the equal protection of the laws applies to these corporations. We are all of opinion that it does" $" 25$.

A partir do caso Santa Clara, a Suprema Corte dotou as corporações de direitos e privilégios, protegendo as empresas contra qualquer ação dos governos federal ou estaduais que pudesse prejudicar a sua existência, liberdade de atuação, bens ou ativos, sem o "devido processo legal". Esta doutrina, intitulada de "substantive due process of law" foi, na realidade, o meio mais fácil encontrado para proteger o direito de propriedade dos acionistas das corporações da regulação estatal (Twiss, 2001, pp. 63-109; Graham, 1968, pp. 30-2, 414-28; Hurst, 2004, pp. 58-70, 152-4; Horwitz, 1994, pp. 65-107; Hovenkamp, 1991, pp. 42-7, 171-82; Kens, 1997, pp. 217-27, 237-46; Kens, 1998, pp. 101-10; Sklar, 2004, pp. 49-53; Beatty, 2007, pp. 16679). Um bom exemplo desta visão que se torna dominante na Suprema Corte entre 1880 e 1937 é a argumentação de John Norton Pomeroy utilizada durante o julgamento do caso San Mateo: "[I]f corporations are not embraced within the guaranties of the Fourteenth Amendment, then the States may so legislate as to deny to all corporations, or to any class of them, such as railroads, ... [their rights and] property without due process of law, and against such legislation There would be no redress, no protection, no prevention. In short, the States might with impunity confiscate the thousands of millions of capital invested in the railroads of the country. The Fourteenth Amendment may prove to be the only bulwark and safeguard by which to protects the great railroad systems of the country against

${ }^{25}$ Santa Clara County v. Southern Pacific R. R. - 118 U. S. 394, p. 396. 
the spirit of communism which is everywhere threatening their destruction or confiscation" $"$.

O conceito de propriedade foi, deste modo, ampliado para o uso e troca de bens e valores tangíveis e intangíveis. Como bem observou um autor do início do século XX, John R. Commons (2007, p. 18), em seu livro célebre Legal Foundations of Capitalism, escrito em 1924: "the definition of property itself had been changed from physical things to the exchange value of anything”.

E, mais adiante: "One is Property, the other is Business. The one is property in the sense of Things owned, the other is property in the sense of exchange-value of things. One is physical objects, the other is marketable assets".

De acordo com a interpretação de William Novak (1996, pp. 245-8), a mitologia liberal da distinção entre Estado e sociedade na esfera econômica se consolida justamente com a ascensão do direito constitucional norte-ame126 ricano após a Guerra Civil: "The invention of American constitutional law was the final linchpin in a new governamental regime that radically separated private right and public power in simultaneous pursuit of a centralized State and an individualized subject. The result was modern American liberalism - the way we currently tend to break up and analyze the legal-political world. The conventions and mythologies of this twentieth-century American liberalism have made it only that much harder to reconstruct and interpret the nineteenth-century well-regulated society" (Novak, 1996, p. 247).

A inversão da constituição, assim, dá as bases jurídicas para a reconstrução empresarial da sociedade norte-americana a partir do final do século XIX. As corporações vão se livrar de boa parte dos controles públicos sobre sua atuação. A própria necessidade de aprovação legislativa das "charters" vai ser, no decorrer do século XIX, abandonada. Neste sen-

\footnotetext{
${ }^{26}$ John Norton Pomeroy in Arguments and Decisions, County of San Mateo v. Southern Pacific Railroad, Stanford University Library apud Graham, 1968, p. 403.
} 
tido, o Estado de New Jersey é o primeiro a elaborar uma "Lei Geral das Corporações" ( "New Jersey's Corporation Law"), em 1889, permitindo a incorporação "for any lawful business or purpose whatever" (Horwitz, 1994, pp. 83-5). Como bem afirmou o historiador Richard Hofstadter (2006, p. 252; Sklar, 2004, p. 5), a questão da empresa ("corporation question" ou "trust question"), não era nada menos do que a real questão sobre de quem era o controle do país.

Controle este que vai ser reafirmado no célebre caso Lochner v. New York, de $1905^{27}$, em que se completou o processo de interpretar o "laissez faire" como parte essencial do texto constitucional norte-americano e como limite a toda e qualquer atuação do Estado, inclusive na esfera dos direitos do trabalho (Twiss, 2001, pp. 111, 130-8; Kens, 1998, pp. 89-95, 111-42; Gillman, 2004, pp. 125-31, 147-93; Fiss, 2006, pp. 155-184). Um dos votos dissidentes, o do Juiz Oliver Wendell Holmes, foi explícito ao acusar a Suprema Corte de adotar as teorias do darwinismo social defendidas por Herbert Spencer: "The 14th Amendment does not enact Mr. Herbert Spencer's Social Statics" ${ }^{\text {"28. }}$.

A hostilidade do Poder Judiciário norte-americano ao movimento organizado dos trabalhadores foi crescente no final do século XIX e início do século $\mathrm{XX}^{29}$. A união de trabalhadores era vista como a mais violenta e ameaçadora forma de concentração de poder econômico, visando a dominação, por um grupo, de um determinado mercado

\footnotetext{
${ }^{27}$ Lochner v. New York - 198 U.S. 45 (1905).

${ }^{28}$ Lochner v. New York - 198 U.S. 45, p. 75. Para uma ampla análise da influência de Spencer e do darwinismo social nos Estados Unidos, ver o hoje clássico Hofstadter, 1992, pp. 31-50, 143-169. Ver, ainda, Kens, 1998, pp. 70-88, 136-142.

${ }^{29}$ Um dos principais casos que ilustram a perseguição do movimento trabalhista por parte das autoridades judiciais é o caso In Re Debs - 158 U. S. 564 (1895), no qual foi condenado Eugene Debs, líder da American Railway Union, com sede em Chicago, após a realização da célebre greve contra a companhia ferroviária Pullman, em 1894. A reação do Poder Judiciário norte-americano, e da Suprema Corte em particular, foi tão radical que alguns autores a traduzem como equivalente a uma declaração de guerra aos sindicatos (Fiss, 2006, pp. 53-74; Beatty, 2007, pp. 269-302).
} 
de trabalho e ameaçando a lei e a ordem pública. O mercado de trabalho, portanto, era entendido como se fosse um mercado como qualquer outro, sem nenhuma distinção. Ao mesmo tempo em que os juízes entendiam que a combinação de capitais poderia ser, em determinados casos, benéfica para a coletividade (com diminuição de preços, economia de escala, melhores produtos, etc), a organização coletiva do trabalho sempre era vista como prejudicial a todos, pois acarretaria fatalmente o aumento de preços e se desencorajaria a "eficiência industrial". Os sindicatos de trabalhadores e a realização de greves e boicotes foram, assim, severamente punidos pelos juízes norte-americanos, sob a alegação de que estariam violando a proteção ao comércio interestadual, garantido pelo Interstate Commerce Act, de 1887, e estariam conspirando contra a realização de negócios ou para restringir o comércio, conduta proibida pela seção I da lei antitruste, o Sherman Antitrust Act, de 1890 128 (Forbath, 1991, pp. 59-97; Hovenkamp, 1991, pp. 207-38; Gillman, 2004, pp. 86-99, 114-25). A aplicação da legislação antitruste contra os sindicatos foi confirmada pela Suprema Corte na decisão do caso Loewe v. Lawlor, em $1908^{30}$.

Nem a aprovação, pelo Congresso norte-americano, de uma legislação que expressamente excluiu as relações de trabalho da esfera do combate aos trustes e cartéis, mudou a posição do Poder Judiciário. O Clayton Act, de 1914, era explícito ao afirmar, em sua seção 6, que "labor of a human being is not a commodity". No entanto, a Suprema Corte continuou, até a década de 1930, a legitimar a aplicação da legislação de defesa da concorrência contra os sindicatos e organizações de trabalhadores, alegando que o Clayton Act não havia modificado nada, pelo contrário, em sua seção 20, inclusive,

\footnotetext{
${ }^{30}$ Loewe v. Lawlor - 208 U.S. 274 (1908). Segundo os dados de Hovenkamp, entre 1890 e 1897, as cortes inferiores condenaram treze casos por violação à legislação antitruste. Destes treze casos, apenas um era de associação de capitais. Todos os doze restantes eram casos de condenação de sindicatos (Hovenkamp, 1991, p. 229).
} 
descrevia os procedimentos que a Corte já vinha utilizando na proteção da propriedade privada (Forbath, 1991, pp. 14758; Hovenkamp, 1991, pp. 236-8).

Da década de 1880 até 1937, a Suprema Corte utilizou as teorias defendidas por Stephen Field, que se aposentou em 1897, para derrubar boa parte da legislação econômica e social governamental, vinculando a ideologia do "laissez-faire" à Constituição de 1787. Alguns, inclusive, denominam este período de "Lochner Era". Há uma série de autores que defendem que este "laissez-faire constitutionalism", na realidade, teria suas origens nas tradições libertárias norte-americanas da época de Andrew Jackson (1829-1837) e na defesa radical da liberdade de trabalho feita antes da Guerra Civil. Nesta tradição, fundada em um individualismo radical, a melhor forma de se garantir a liberdade seria limitar os poderes do governo, vinculado politicamente às elites. Mesmo tendo por origem essa tradição jacksoniana, a defesa das posições de Stephen Field e de seus sucessores na Suprema Corte não significa que não tenha havido influência da doutrina econômica do "laissez-faire", nem significa que a adoção desta concepção liberal econômica radical não tenha alterado o sentido do texto constitucional norte-americano, ampliando ao máximo o impacto da chamada "contract clause" (Graham, 1968, pp. 379-81, 391403; McCurdy, 1975, pp. 973-87; Gold, 1983, pp. 261-8; Les Benedict, 1985, pp. 317-31; Hovenkamp, 1991, pp. 28-35; Kens, 1997, pp. 4-10, 49-52, 62-5, 254-6, 264-275; Kens, 1998, pp. 154-76, 182-4; Gillman, 2004, pp. 33-60; Beatty, 2007, pp. 113-4, 179-83).

A Suprema Corte norte-americana foi transformada em uma corte econômica. O seu "laissez faire" judicial foi agravado e levado aos limites do darwinismo social, com menções 
expressas a Herbert Spencer, inclusive. Com o caso Lochner, a Suprema Corte reteve a jurisdição sobre todas as questões constitucionais que envolvessem o direito de propriedade, tornando-se uma espécie de "árbitro econômico" da Nação e protetora do poder econômico privado (Twiss, 2001, pp. 256-9; Lerner, 1932-1933, pp. 684-6, 696-701) ${ }^{31}$.

Este estado de coisas perduraria praticamente inabalado até a crise do capitalismo mundial, iniciada em 1929. A soberania popular ressurgirá ao conceder, pelo voto, a legitimidade para que um Presidente, considerado até hoje por muitos como um "traidor da sua classe" (Brands, 2008), conseguisse reforçar os poderes de intervenção do Estado nas esferas econômica e social, em uma verdadeira emergência econômica, e, com isso, consolidar o Governo Federal como governo verdadeiramente nacional, enfrentar a Suprema Corte, ampliar a preponderância do Executivo, com base na crença de que haveria uma relação direta 130 entre a vontade popular e a vontade do Presidente, e preparar o seu país para a batalha mundial que se avizinhava contra o fascismo ${ }^{32}$.

\footnotetext{
${ }^{31}$ Houve, obviamente, reações à elevação da liberdade contratual a princípio constitucional sagrado. Vários juristas progressistas criticaram as posições da Suprema Corte, demonstrando a sua defesa dos privilégios dos setores economicamente dominantes em detrimento do interesse público e da maioria da população. Um exemplo paradigmático deste tipo de crítica é o célebre ensaio de Roscoe Pound sobre a liberdade contratual, em que o autor denuncia a "falácia" da argumentação empregada nas decisões judiciais, exigindo uma firme atuação do Poder Legislativo em sentido contrário ao dado pela Suprema Corte, cuja autoridade teria sido irremediavelmente comprometida com esse tipo de decisão (Pound, 1908-1909). Outro texto do mesmo autor crítico às decisões da Suprema Corte é Pound (1908, pp. 614-22). Ver também Beatty (2007, pp. 159-62).

${ }^{32}$ Com o recrudescimento do conservadorismo nos Estados Unidos a partir da Presidência de Ronald Reagan (1980-1988), recrudescimento este cuja manifestação contemporânea mais pitoresca é o chamado "tea party", surgem autores que defendem não apenas a correção da decisão do caso Lochner $v$. New York, como a necessidade de aplicação de seus parâmetros ainda hoje, pois sua concepção social e econômica corresponderia efetivamente à vontade dos chamados "Framers" da Constituição (Kens, 1998, pp. 184-187; Siegan, 1985, pp. 492-497).
} 


\section{Gilberto Bercovici}

é professor titular da faculdade de direito da Universidade de São Paulo e bolsista de produtividade do CNPq.

\section{Referências bibliográficas}

ADAMS, W. P. 2001. The first American constitutions: republican ideology and the making of the state constitutions in the revolutionary era. Lanham: Rowman \& Littlefield.

AQUARONE, A. 1959. Due costituenti settecentesche: note sulla convenzione di filadelfia e sulla assemblea nazionale francese. Pisa: Nistri-Lischi.

BEARD, C. A. 1986. An economic interpretation of the constitution of the United States. New York: Free Press.

BEATTY, J. 2007. Age of betrayal: the triumph of money in America, 18651900. New York: Alfred A. Knopf.

BRANDS, H. W. 2008. Traitor to his class: the privileged life and radical presidency of Franklin Delano Roosevelt. New York/London: Doubleday.

COMMONS, J. R. [1924] 2007. Legal foundations of capitalism. New Brunswick/London: Transaction.

FEHRENBACHER, D. E. 2001. The Dred Scott case: its significance in American law and politics. Oxford/New York: OUP.

2005. The slaveholding republic: an account of the United States government's relations to slavery. Oxford/New York: Oxford University Press.

FISS, O. M. 2006. Troubled beginnings of the modern state, 1888-1910. Cambridge/New York: CUP.

FORBATH, W. E. 1991. Law and the shaping of the American labor movement. Cambridge (Ma.)/London: HUP.

FRIEDMAN, L. M. 2005. A history of American law. New York/London: Touchstone.

GILLMAN, H. 2004. The constitution besieged: the rise and demise of Lochner era police powers jurisprudence. Durham/London: Duke University Press.

GOLD, D. M. 1983. "Redfield, railroads, and the roots of 'laissez-faire constitutionalism'”. The American Journal of Legal History, v. 27, n. 3, pp. 254-68.

GRAHAM, H. J. 1968. Everyman's constitution: historical essays on the fourteenth amendment, the "conspiracy theory", and American constitutionalism. Madison: State Historical Society of Wisconsin.

HAMILTON, A. 2001. "Address of the Annapolis convention". In:

Writings. New York: The Library of America, pp. 142-5. 
et al. 1987. The federalist papers. London/New York: Penguin Books.

HANSON, R. L. 1988. “'Commons' and 'commonwealth' at the American founding: democratic republicanism as the new American hybrid". In: BALL, T.; POCOCK, J. G. A. (coords.). Conceptual change and the constitution. Lawrence: University Press of Kansas, pp. 165-193.

HINTZE, O. 1964. "Wirtschaft und Politik im Zeitalter des modernen Kapitalismus". In: Soziologie und Geschichte: Gesammelte Abhandlungen zur Soziologie, Politik und Theorie der Geschichte. Göttingen: Vandenhoeck \& Ruprecht, pp. 427-452.

HOFSTADTER, R. 1992. Social Darwinism in American thought. Boston: Beacon Press.

2006. The age of reform: from Bryan to FDR. New York: Vintage Books.

HORTON, J. O.; HORTON, L. E. 1997. "A federal assault: African-Americans and the impact of the fugitive slave law of 1850". In: FINKELMAN, P. (org.). Slavery and the law. Lenham/Boulder/New York/Oxford: Rowman \& Littlefield, pp. 143-160.

HORWITZ, M. J. 1990. The transformation of American law, 1780-1860. Cambridge, MA/London: HUP.

1994. The transformation of American law, 1870-1960: the crisis of legal orthodoxy. Oxford/New York: OUP.

132 HOVENKAMP, H. 1991. Enterprise and American law 1836-1937. Cambridge MA/London: HUP.

HURST, J. W. 2004. The legitimacy of the business corporation in the law of the United States, 1780-1970. Clark: The Lawbook Exchange.

KACZOROWSKI, R. J. 2002. "The inverted constitution: enforcing constitutional rights in the nineteenth century”. In: VANBURKLEO, S. F. et al. (orgs.). Constitutionalism and American culture: writing the new constitutional history. Lawrence: University Press of Kansas, pp. 29-63

2005. The politics of judicial interpretation: the federal courts, department of justice, and civil rights, 1866-1876. New York: Fordham University Press.

KENS, P. 1997. Justice Stephen Field: shaping liberty from the gold rush to the gilded age. Lawrence: University Press of Kansas.

1998. Lochner $v$. New York: economic regulation on trial. Lawrence: University Press of Kansas.

LERNER, M. 1933. "The supreme court and American capitalism". Yale Law Journal, v. 42, n. 5, pp. 668-701.

LES BENEDICT, M. 1985. "Laissez-faire and liberty: a re-evaluation of the meaning and origins of laissez-faire constitutionalism”. Law and History Review, v. 3, n. 2, pp. 293-331. 
LEVINSON, S. 1997. "Slavery in the canon of constitutional law". In: FINKELMAN, P. (org.). Slavery and the law. Lenham/Boulder/New York/Oxford: Rowman \& Littlefield, pp. 89-111.

LYND, S. 1980a. "The abolitionist critique of the United States constitution”. In: Class conflict, slavery, and the United States constitution: ten essays. Westport: Greenwood, pp. 153-83.

1980b. "The compromise of 1787" In: Class conflict, sla-

very, and the United States constitution: ten essays. Westport: Greenwood, pp. 185-213.

McCURDY, C. W. 1975. "Justice field and the jurisprudence of government-business relations: some parameters of laissez-faire constitutionalism, 1863-1897". The Journal of American History, v. 61, n. 4, pp. 970-1005.

McDONALD, F. 1982. Alexander Hamilton: a biography. New York/London: W. W. Norton \& Company.

1985. Novus ordo seclorum: the intellectual origins of the constitution. Lawrence: The University Press of Kansas.

MORGAN, E. S. 1989. Inventing the people: the rise of popular sovereignty in England and America. New York/London: W. W. Norton.

NOVAK, W. J. 1996. The people's welfare: law and regulation in nineteenth-century America. Chapel Hill/London: The University of North Carolina Press.

POUND, R. 1908. "Mechanical jurisprudence”. Columbia Law Review, v. 8, pp. 605-623.

1909. "Liberty of contract". Yale Law Journal, v. 18, n. 7, pp. 454-487.

RICHARDS, L. L. 2003. Shays's rebellion: the American revolution's final battle. Philadelphia: University of Pennsylvania Press.

SEELAENDER, A. C. L. 2009. "A 'polícia' e as funções do estado: notas sobre a 'polícia' do antigo regime". Revista da Faculdade de Direito - UFPR, n. 49 , pp. 74-81.

SIEGAN, B. H. 1985. "Rehabilitating Lochner". San Diego Law Review, v. 22, n. 2-3, pp. 453-497.

SKLAR, M. J. 2004. The corporate reconstruction of American capitalism, 18901916. Cambridge/New York: Cambridge University Press.

STOURZH, G. 1970. Alexander Hamilton and the idea of republican government. Stanford: Stanford University Press.

SZATMARY, D. P. 1980. Shays' rebellion: the making of an agrarian insurrection. Amherst: The University of Massachusetts Press.

TRIBE, K. 2007. Strategies of economic order: German economic discourse 1750-1950. Cambridge/New York: CUP. 
TWISS, B. R. 2001. Lawyers and the constitution: how laissez-faire came to the supreme court. Union: The Lawbook Exchange [facsimile].

WALDSTREICHER, D. 2009. Slavery's constitution: from revolution to ratification. New York: Hill and Wang.

WOOD, G. S. 1998. The creation of the American republic, 1776-1787. Chapel Hill/London: The University of North Carolina Press. 


\section{A CONSTITUIÇÃO INVERTIDA: A SUPREMA CORTE AMERICANA NO COMBATE À AMPLIAÇÃO DA DEMOCRACIA}

\section{GILBERTO BERCOVICI}

Resumo: O presente texto oferece uma análise histórica das limitações à soberania popular plena nos Estados Unidos desde a Independência até o início do século XX, destacando o papel ativo da Suprema Corte no combate à ampliação da democracia norte-americana. O empenho da Suprema Corte na extensão da garantia dos direitos dos proprietários de escravos antes da Guerra Civil revela a força da rejeição da mesma Suprema Corte à realização dos direitos fundamentais incorporados à constituição pelas $13^{\mathrm{a}}$ e $14^{\mathrm{a}}$. Emendas, depois da Guerra Civil, transformando o discurso da "Constituição de todos" na realidade da "Constituição invertida".

Palavras-Chave: Soberania Popular; Democracia; História Constitucional Americana

\section{THE INVERTED CONSTITUTION: THE AMERICAN SUPREME COURT IN THE FIGHT AGAINST THE AMPLIATION OF DEMOCRACY}

Abstract: The text presents a historical analysis to the limits of the full popular sovereignty in the United States from the Independence to the beginning of the $20^{\text {th }}$ century, focusing on the active role of the Supreme Court as an opponent to the expansion of the North-American democracy. The vigorous efforts of the Supreme Court in order to extend the warrants of the slave owner's rights before the Civil War reveal how strong the same Court repelled the recognition of fundamental rights incorporated to the Constitution by the $13^{\text {th }}$ and $14^{\text {th }}$ Amendments after the Civil War, transfiguring the "everyman's Constitution" speech into the reality of the "inverted Constitution".

Keywords: Copular Sovereignty; Democracy; American Constitutional History 